\title{
Fabrication of Nanoparticles of Sulfated Low Methoxyl Pectin by Cross-linking Reaction on Ionotropic Gelation Technique
}

\author{
Sri Usmiati* ${ }^{*}$, Djumali Mangunwidjaja ${ }^{2}$, Erliza Noor ${ }^{3}$, Nur Richana ${ }^{4}$ and Endang \\ Prangdimurti ${ }^{5}$ \\ ${ }^{1,4}$ Indonesian Center for Agricultural Postharvest Research and Development, \\ Jl. Tentara Pelajar No. 12, Kampus Penelitian Pertanian Cimanggu, Bogor \\ 16114, Indonesia \\ 2,3 Department of Agroindustrial Technology, Faculty of Agricultural Engineering \\ and Technology, Bogor Agricultural University, \\ Kampus IPB Darmaga PO Box 220, Bogor 16002, Indonesia \\ ${ }^{5}$ Department of Food Science and Technology, Faculty of Agricultural \\ Engineering and Technology, Bogor Agricultural University, \\ Kampus IPB Darmaga PO Box 220, Bogor 16002, Indonesia \\ "1 usmiati_sri@yahoo.co.id; ${ }^{4}$ rich4n4@yahoo.co.id, ${ }^{2}$ jumalimw@hotmail.com ; \\ 3 erlizanoor@yahoo.com,prangdimurti@ipb.ac.id
}

\begin{abstract}
The sulfation process on pectin produces a number of sulfate groups replacing hydroxyl groups within low methoxyl pectin (LMP) chains. A structure alteration due to the sulfation process may results in changes in LMP characteristics. The LMP sulfation process was aimed to reach an increase in pectin functionality in terms of bioactivities. To gain sulfated LMP (sLMP) performance, the ionic gelation process was undertaken so as sLMP nanoparticles were obtained through cross-linking reactions with divalent cations. The sulfation process on sLMP was conducted by employing different volume of $\mathrm{SO}_{3}$-DMF solvent. According to the Fourier Transform Infrared (FTIR) spectroscopy analysis, pectin was successfully sulfated indicated by the presence of $-S$ groups within pectin chains. The sulfation process with solution of $\mathrm{SO}_{3}-\mathrm{DMF} 9.0 \mathrm{~mL}$ indicated the best results, i.e. sulfated percentage of $43.63 \%$ with the sulfate content of $0.302 \%$ and degree of sulfation of 0.0155. Sulfated LMP formed nanoparticles in a formula combination of LMP:sLMP (a ratio of 1:1) with a composition of pectin of $2 \%$ and $\mathrm{CaCl}_{2}$ of $0.8 \%$. The nanoparticles of sulfated pectin was relatively stable at cool temperature storage.
\end{abstract}

Keywords: pectin sulfation, $\mathrm{SO}_{3}-D M F$, sulfate content, nanoparticles, stability

\section{Introduction}

Biochemistry researchers and nutritionists nowadays pay great attention to polysaccharide since it has a broad spectrum of biological activities [1]. It was reported that some polysaccharide activities already discovered comprising an immunity increase, antitumor, antiviral, antioxidant and hypoglycemic effects. Numerous evidences show that biological activities of polysaccharide are relied on its structure, among others, on the sulfate degree [2]. Sulfate and hexauronic acid within the sulfated-polysaccharide fraction of an Ophiopogon japonicus tuber root are effective indicators of antioxidant and immunomodulatory activities [3].

\footnotetext{
${ }^{*}$ Corresponding Author : usmiati_sri@yahoo.co.id
} 
Sulfated polysaccharide is a polysaccharide highly containing sulfate groups. Some polysaccharides reported containing naturally sulfates are glucan, chitosan, dextran, pullulan and others [4]. Natural sulfated polysaccharides such as fucan and galactan originating from sea invertebrates were reported having excellent biological activities [5, 6]. However, these polysaccharides commonly are found in a limited number. Based on the many benefits offered by the biological activity of the sulfated polysaccharide, it is necessary to increase its availability.

Sulfated polysaccharide is more often obtained through chemical modifications [7]. Chemical modifications on polysaccharide are performed to attain new functions, engender more active derivatives, or enhance its functions. Modifications through sulfation is replacement of hydroxyl groups within polymers with sulfate groups for the purpose of enhancing effects of polysaccharide physiological functions, for example, anticoagulant, antitumor and anti-HIV functions [8,-9]. Sulfation reactions involve entire primary and secondary hydroxyls within polysaccharide. Jung et al. [4] working sulfation on polysaccharide extracted from Pleurotus eryngii fungus reported that it was effective in inhibiting cancer cell growth. According to [10], sulfation on derived polysaccharide of an Auricularia auricular fungus showed antioxidant activity, and it indicated a novel type of immunopotentiator [11].

There are many chemical agent able to be used for either the process of sulfonation or sulfation the polysaccharides. These compounds include liquid or gas-phase sulfur trioxide $\left(\mathrm{SO}_{3}\right)$, concentrated sulfate-acid solution (93-98\%), oleum, chlorosulfonic acid and sulfur dioxide. In addition, pyridine, piperidine $\mathrm{N}$-sulfonate acid or complexes of sulfur trioxide and pyridine, tri-ethylamine or DMF may be used [12], formamide and DMSO are also regularly used as solvents in sulfated polysaccharide reactions. As stated by [13], chlorosulfonic acid is the most optimal reagent for chemical sulfatation. Chlorosulfonic acid is made of chloride acid and sulfur trioxide by the reaction of $\mathrm{SO}_{3}+$ $\mathrm{HCl}=\mathrm{ClSO}_{2} \mathrm{OH}$.

Among of various types of polysaccharides, pectin is a polysaccharide that is widely used in human's lives. Pectin comprises one of polysaccharide types widely applied as functional components in foods and pharmaceuticals. Pectin has effects able to decrease cholesterol levels [14], decelerate gastric emptying [15], induce apoptosis of colonic cancer cells [16], be a combined material to extend hormonal and antibiotic works, as well as be an injection material to prevent bleeding [17]. It is upon the fact that pectin is resistant to protease and amylase, enzymes active in the upper gastrointestinal tract. Moreover, pectin is found as a wonderful biopolymer as it is highly degradable and biocompatible. This polysaccharide is recorded non-toxic and abundantly available.

Pectin, especially LMP, is capable to form unique gels with divalent cations and crosslinks in the ionic gelation process, therefore make it ideal as a bioactive delivery agent. This polysaccharide is able to develop aggregation at low $\mathrm{pH}$. The level of acidity of solution contributes to the ionization level of pectin molecules and the electrostatic interaction with cations. At $\mathrm{pH} 4$ the ionization level of pectin molecules is considered high [18]. This consequently enables strong bonds between negative charges of hydroxyl ions within pectin and positive charges of calcium ions, thereby resulting in small particle sizes. Pectin mostly is applied as a colon-specific delivery device, since at neutral $\mathrm{pH}$ or nearly neutral in the colon, pectin aggregates will be dissociated and form long chains. Based on those physicochemical properties, the LMP can be used as a candidate of sulfated polysaccharide by giving the sulfur ions in the side chain of free carboxyl groups through sulfation process. In the form of sulfated pectin, hopefully it has a good biology activities for human's health.

Biodegradable and biocompatible polymers that are suitable for human use can be prepared as particle complexes in various sizes. Nowadays, nanoparticles have attracted the attention of researcher to be applied as a delivery agent of macromolecular bioactives such as peptides, proteins and gens due to its capability protecting labile components from 
enzymatic reactions. Moreover, the endocytic uptake of nanoparticles leads to broken barrier permeability as a consequence of epithelial absorption. Particles whose charges and sizes are compatible are able to enter into mammalian cells through different routes, and in other words this may enhance opportunities to enter into cells. By arranging some important process parameters, LMP can be fabricated into nanoparticles by means of crosslinking in the ionic gelation process. Low methoxyl pectin in the form of nanoparticles are expected as a delivery agents that are more resistant to harsh condition for sensitive bioactives into targeted organs in the human body.

Pursuant to literatures, it appears that specific studies on sulfation of LMP prepared for producing nanoparticles have never been reported. However, to do this research there is a fundamental problem. The addition of sulfate groups into the pectin chain is likely to affect the physicochemical properties of sulfated LMP. According to [4], solubility of sulfated polysaccharide in water undergoes an increase. The solubility changes caused difficulties in the formation of particles of ionic gelation in the cross-linking reaction between sLMP and cation. It is caused by a reduction the anionic groups of LMP after the sulfation process. Therefore, it is necessary to study extensively for searching the techniques, methods or ways to overcome the problems. This work was aimed to chemically modify low methoxyl pectin derived from lime (Citrus aurantifolia Swingle) peel through the sulfation process as a material for production of a relatively stable nanoparticle functioning as a colon-specific delivery agent.

\section{Materials and Methods}

\subsection{Preparation of Low Methoxyl Pectin for the Sulfatation Process}

This research employed LMP (extracted from Citrus aurantifolia Swingle lime peel) with the DE of $45.77 \%$ for the sulfation process. Pectin sulfation was carried out in accordance with method of [19] with a slight modification. The reagent for $\mathrm{SO}_{3}-\mathrm{DMF}$ sulfation was prepared by dripping $50 \mathrm{~mL}$ of $\mathrm{HClSO}_{3}$ into an Erlenmeyer containing 300 $\mathrm{mL}$ of DMF (N,N-dimethyl formamide) and cooled in a container filled by iced water. Dried pectin $(1.0 \mathrm{~g})$ was added into $40 \mathrm{~mL}$ of formamide, followed by the mixture stirred at $80^{\circ} \mathrm{C}$ within 3 hours for the purpose of distribution in the solvent. Next, the $\mathrm{SO}_{3}-\mathrm{DMF}$ reagent (sulfation reagent volumes of $6.0 ; 7.5 ; 9.0 ; 10.5$; and $12 \mathrm{~mL}$ ) was added into the mixture. After 3 hours, the mixture was cooled at room temperature and precipitated with $75 \%$ alcohol for 24 hours. Precipitates then were filtered and rinsed three times in 60\% alcohol and put into $100 \mathrm{~mL}$ of aquadest. The solution then were neutralized with 1 $\mathrm{mol} / \mathrm{mL}$ of $\mathrm{NaOH}$ solution and dialyzed in flowing water for 72 hours using a 2000 NMWCO (nominal molecular weight cut-off) pore-sized dialyzing membrane or 2000 $\mathrm{kda}$. The mixture then was dried in an oven at $50^{\circ} \mathrm{C}$. Dried sulfated-pectin was characterized upon structure parameters employing the FTIR, the percentage of sulfated pectin products as well as the sulfate content and degree of substitution.

\subsection{The Analysis of Sulfated LMP Profile}

\section{a. FTIR (Fourier Transform Infrared) Spectroscopy}

A two mg of sample and $200 \mathrm{mg}$ of $\mathrm{KBr}$ were ground and mixed until homogenous and put in a disc molding apparatus, molded into $\mathrm{KBr}$ pellets. The pellet sample was put into a sample pan in the FTIR apparatus, and measured at $4000 \mathrm{~cm}-1$ to $450 \mathrm{~cm}-1$ wave length.

\section{b. Degree of Substitution}

This step was started by making of $\mathrm{BaCl}_{2}$-gelatin solution. One gram of gelatin and 200 $\mathrm{mL}$ of aquadest were mixed then heated at $60^{\circ}-70^{\circ} \mathrm{C}$ until the gelatin was dissolved. The gelatin solution was stored in the refrigerator within 6 hours or overnight. One gram of $\mathrm{BaCl}_{2}$ was mixed into the solution and homogenized, then stored again in the refrigerator 
for one week. Meanwhile, the mother liquor of $\mathrm{Na}_{2} \mathrm{SO}_{4}$ (concentration of $100 \mathrm{ppm}$ ) was made in separately flask. A 0.0148 gram of $\mathrm{Na}_{2} \mathrm{SO}_{4}$ was put into a $100 \mathrm{~mL}$ - flask then dissolved in aquadest up to the mark terra. From the mother liquor the standard solution was prepared. Each of the 5, 10, 15, 20, and $25 \mathrm{~mL}$ volumes from the mother liquor was put into a $100 \mathrm{~mL}$-flask at each concentration of 5,10,15,20, and $25 \mathrm{ppm}$ then dissolved in aquadest up to the terra mark. Absorbance was measured by a UV-VIS spectrophotometer at $420-\mathrm{nm}$ wave length. The sample solution was prepared with following steps. Two miligrams of sample was dissolved in $2 \mathrm{~mL}$ of aquadest then $5 \mathrm{ml}$ of Trichloro Acetic acid of $4 \%$ was added in a closed tube. The mixture was heat in a water bath at $100^{\circ} \mathrm{C}$ within 4 hours then cooled at room temperature. Before the tube was opened, the solution was shaken and $1 \mathrm{ml}$ was taken before put into a centrifuge. Two mililiter of aquadest and $1 \mathrm{ml}$ of the $\mathrm{BaCl}_{2}$-gelatin solution were added and centrifuged within 1 minute. Absorbance was measured employing a UV-VIS spectrophotometer at $420 \mathrm{~nm}$ wave length. The sulfur content contained in the sample was obtain after the sulfate concentration was calculated, followed by the sulfate degree of substitution calculated using this following formula:

$$
\mathrm{DS}=\frac{162 \times \mathrm{S} \% / 32}{100-(80 / 32 \times \mathrm{S} \%)}
$$

Descriptions:

$\begin{array}{ll}\text { DS } & =\text { degree of substitution } \\ 162 & =\text { the molecular weight of glucose } \\ 80 & =\text { molecular weight of sulfate groups } \\ 32 & =\text { the molecular weight of sulfur atom } \\ \text { S\% } & =\text { concentration of sulfuric }\end{array}$

\subsection{The Ionic Gelation Cross-linking Process in Sulfated LMP Nanoparticle Formation}

In order to reach the nanoparticle sLMP this study was designed with steps as follows:

\section{a. Determination of a ratio between sulfated LMP and cation concentrations producing the nanoparticle size}

The study used a pectin and cation concentration range of $0.01-1 \%$ and the pectin:cation volume ratio of 1:10, the observation was done macroscopically followed by size measurement. The best result was considered according to achievement of the nanometric size and the relatively low value of PDI (PolyDiversity Index).

\section{b. Preparation of sulfated LMP nanoparticles}

This study was conducted by proving occurrence of the ionic gelation process using sLMP, which was marked by the bead formation. The analysis and size measurement were carried out macroscopically. The best result was envisaged based on achievement of the nanometric scale, negative charges and relatively low PDI value.

\section{c. Observation on sulfated LMP nanoparticle stability}

Nanoparticles selected in the (a) step were subjected to measurement of sizes and zeta potentials in 8 points ( 7 weeks) in order to reach relatively stable sLMP nanoparticles. sLMP nanoparticle storage was done at cool temperature $\left(5^{\circ} \mathrm{C}\right)$, room temperature (27$33^{\circ} \mathrm{C}$ ) and $40^{\circ} \mathrm{C}$. A sample observation was also performed macroscopically. 


\section{d. Production of sLMP nanoparticles}

Procedures of sLMP nanoparticle formation [18] were as follows. Both of sulfated low methoxyl pectin and cations employing were dissolved in distilled water to reach the treatment concentrations. Further, $2.0 \mathrm{~mL}$ of the pectin solution (LMP:sLMP=1:1) was dripped into $2 \mathrm{~mL}$ of the cation solution while mixing by a stirrer, at $25^{\circ} \mathrm{C}$. Mixing was continued for 20 minutes. Nanoparticles produced then were collected for the purpose of size and zeta potential analyses.

\section{e. Characterization of sulfated LMP nanoparticle physical-properties}

Particle sizes and zeta potentials were measured from new samples on a Zetasizer Nano $\mathrm{ZS}$ apparatus. For the purpose of analysis, each sample was dissolved in pure water at a suitable concentration and placed in the electrophoretic cell and the analysis was performed at $25^{\circ} \mathrm{C}$.

\subsection{Statistical Analysis}

The analysis of sulfated low methoxyl pectin samples was conducted in three replicates in a completely randomized design (CRD). The statistical analysis was done by employing the statistical analysis of SPSS for windows (ver. 17). A Duncan Test was applied to evaluate any significant difference among mean values at the $95 \%$ confidence level $(\mathrm{P}<0.05)$.

\section{Results and Discussion}

\subsection{Sulfated LMP Characterization}

\section{a. The FTIR spectroscopy analysis}

An analysis of the FTIR spectroscopy was applied to observe molecular vibrations and polar bonds between different atoms. The FTIR spectroscopy analysis allows to be done against polysaccharide structures such as monosaccharide, glycosidic bonds and functional groups [21]. Figure 1 was FTIR profile of unsulfated LMP (P0), while the presence of sulfur groups within sLMP in this study was presented on Figure 2.

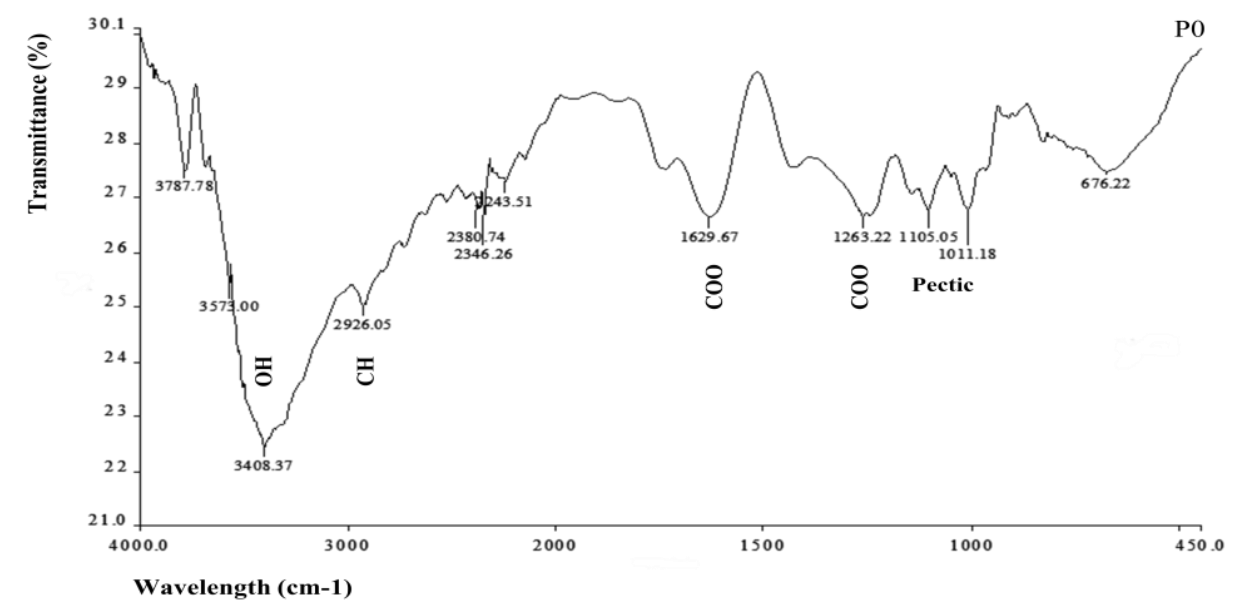

Figure 1. Fourier Transform Infrared of unsulfated low methoxyl pectin

The FTIR spectra in the region between $4000-400 \mathrm{~cm}-1$ identified the major chemical groups in the pectin and provided structural information of pectin. The spectral data obtained were analyzed by comparing the FTIR spectra in the following characteristic 
regions, OH stretching band envelope $3600-3100 \mathrm{~cm}-1$, CH stretch at $3000-2800 \mathrm{~cm}-1$, the fingerprint region of spectra under ca. $2000 \mathrm{~cm}-1$, including the band contributing to resonant absorption energy of pyranose cycle vibrations $1200-950 \mathrm{~cm}-1$, as well as the region 1200-1800 cm-1 featuring the state of carboxylic groups (COO). According to [22], the region 1200-950 cm-1 polysaccharide has a strong absorption as fingerprint, is characteristic of each polymer. The region featuring the state of carboxylic groups of pectin at $1750-1350 \mathrm{~cm}-1$. The band at ca. $1750 \mathrm{~cm}-1$ is assigned to stretching $\mathrm{C}=\mathrm{O}$ mode non-ionized methylated or protonated carboxyl.

The absorption band characteristics appearing in the FTIR spectra of pectin showed in Figures 1 and 2. For the pyranose cycle vibrations region as characteristic for peptic substances of pectin, there were almost identical spectral parts with: bands at 1105 and $1011 \mathrm{~cm}-1$ (P0); 1104 and $1017 \mathrm{~cm}-1$ (P1); 1103 and $1014 \mathrm{~cm}-1$ (P2); $1108 \mathrm{~cm}-1$ (P3); 1111 and $1012 \mathrm{~cm}-1$ (P4); 1152, 1112, 1053 and $1021 \mathrm{~cm}-1$ (P5). All peptic polysaccharides characterized mainly by these peaks, those absorbances were the galacturonic acid. The peak in 3600-3200 cm-1 region showed that there were too many $\mathrm{OH}$ groups in the pectin molecule.

The band centered at $1738 \mathrm{~cm}-1$ in P2 spectral and $1737 \mathrm{~cm}-1$ in P3 spectral parts have been utilized to probe the $\mathrm{DE}$ in pectin. These bands have been assigned to the $\mathrm{C}=\mathrm{O}$ stretching vibration of methyl ester. There are two bands in the lime LMP spectrum within region (a major one and a less intense one). Those two bands correspond, respectively, to asymmetrical and symmetrical stretching vibrations due to the COOgroup of polygalacturonic acid. The bands were: 1629 and 1263 (P0); 1633 and $1240 \mathrm{~cm}$ 1 (P1); 1625 and $1263 \mathrm{~cm}-1$ (P2); $1640 \mathrm{~cm}-1$ (P3); 1635 and $1246 \mathrm{~cm}-1$ (P4); and 1642 and $1235 \mathrm{~cm}-1$ (P5). The spectral parts at $1430 \mathrm{~cm}-1$ (P1), $1436 \mathrm{~cm}-1$ (P2); $1428 \mathrm{~cm}-1$ (P3); $1428 \mathrm{~cm}-1$ (P4); and $1429 \mathrm{~cm}-1$ (P5) were indicating the existence of strong vibration of $\mathrm{S}=\mathrm{O}$ (sulfate) bonds in sLMP.
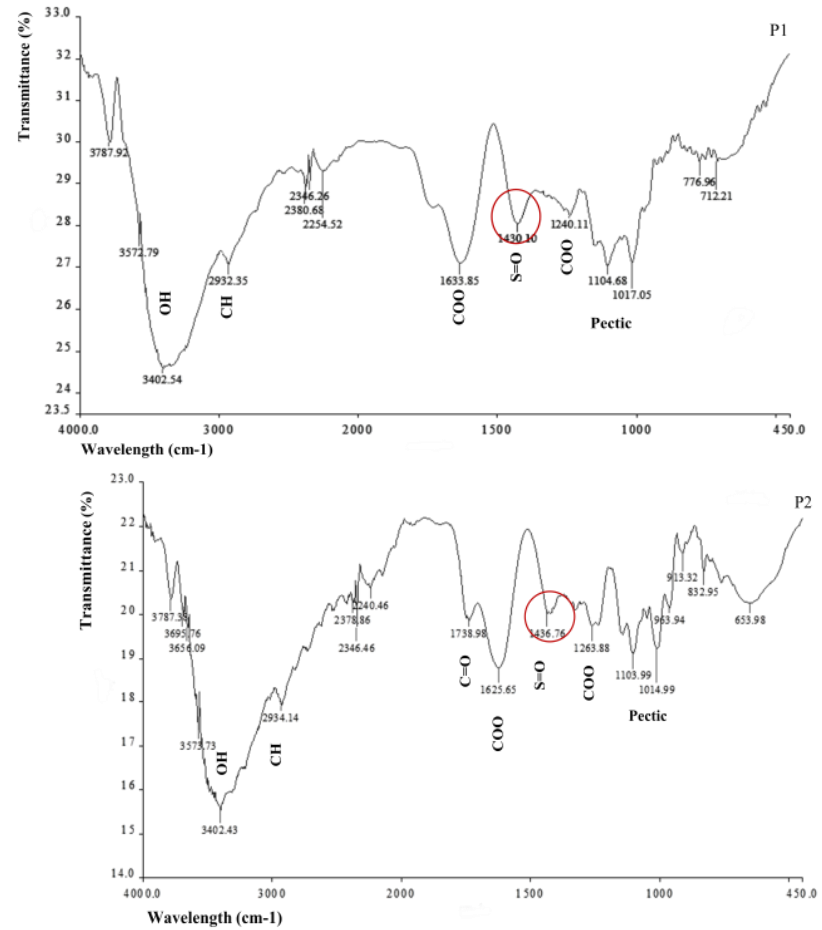

(a)

(b) 

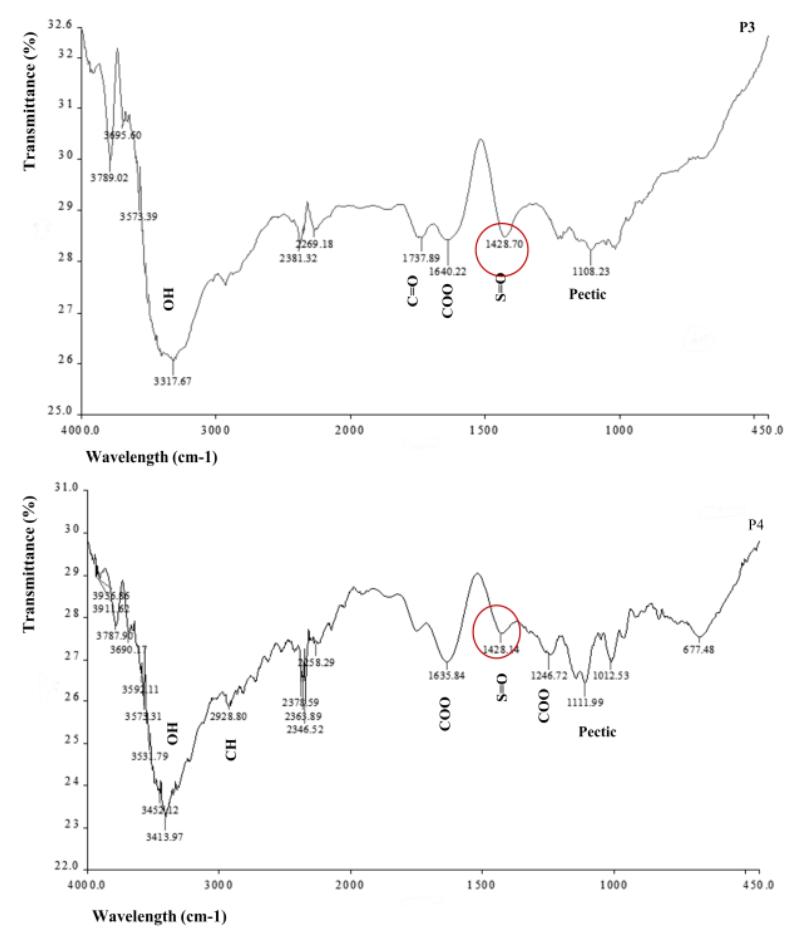

(c) (d)

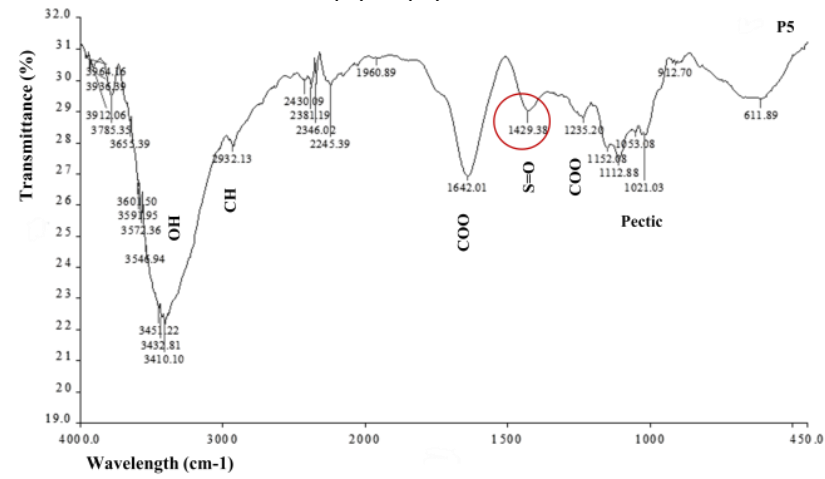

(e)

Figure 2. Fourier Transform Infrared Profile of Pectin using: (a) $6 \mathrm{~mL}$ (P1); (b) $7.5 \mathrm{~mL}$ (P2); (c) $9.0 \mathrm{~mL}$ (P3); (d) $10.5 \mathrm{~mL}$ (P4); and (e) $12.0 \mathrm{~mL}$ (P5)

Based on Figure 2, the FTIR spectra of the sulfation reaction in LMP chain was characterized by those peaks as identified as group of $\mathrm{S}=\mathrm{O}$ (sulphate). Vibrational stretch of the bands was very strong and intense. All of those bands exhibited the presence of bonds with sulfuric compounds. These bonds indicated that polysaccharide have been successfully sulfated [23]. On the basis of FTIR analysis, LMP derived from lime peel had been completely sulfated in all treatments compared with unsulfation LMP. There was no any vibration band indicating the presence of sulfate groups on unsulfated LMP.

\section{b. Yield of sulfated pectin, sulfate contents and degree of substitutions}

In accordance with ANOVA analysis results, treatments were known affecting $(\mathrm{P}<0.05)$ sulfated pectin yield percentages, sulfate contents and degree of substitutions. Figure 3 presents sLMP characteristics. 


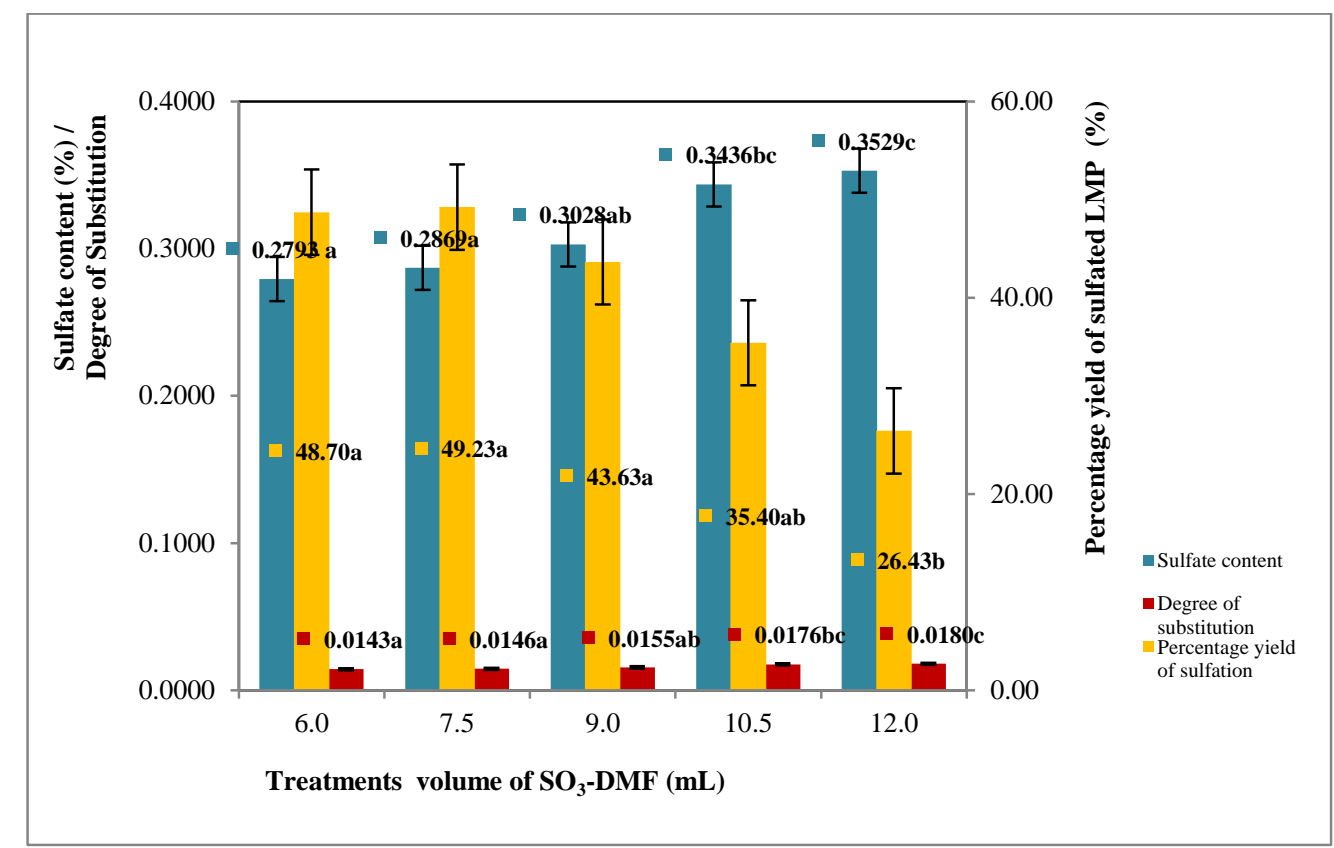

Figure 3. Characteristics of Sulfated Low Methoxyl Pectin from Lime Peel

According to Figure 3, the use of $12.0 \mathrm{~mL}$ of $\mathrm{SO}_{3}-\mathrm{DMF}$ volume for the sulfatation process indicated the lowest yield percentage (26.43\%) compared to other treatments. There was a tendency that as the use of $\mathrm{SO}_{3}$-DMF volume was higher the percentage of sulfated pectin tended to be lower. The use of $12-\mathrm{mL} \mathrm{SO}_{3}$-DMF volume yielding the lowest sulfated pectin ( $0.264437 \mathrm{~g}$ compared to 1 gram of the initial pectin weight) was likely due to the fact that reactions of the polysaccharide changing to other low molecular weight compounds $(<2000 \mathrm{kda})$ passing through pores of dialysis at the time of the dialysis process in flowing water occurred.

Whilst, Figure 3 suggests that the higher $\mathrm{SO}_{3}$-DMF volume use yielded the increasing sulfate content and degree of substitution, consecutively from the treatment of the $6.0-\mathrm{mL}$ $\mathrm{SO}_{3}$-DMF volume with the sulfate content of $0.2793 \%$ and DS of 0.0143 to $12 \mathrm{~mL}$ with the sulfate content of $0.3529 \%$ and DS of 0.0180 . The degree of substitution is the average number of groups per anhydroglucose unit substituted by other groups. In this term, it indicated the number of sulfate groups $(\mathrm{S})$ substituting hydroxyl $(\mathrm{OH})$ groups on galacturonic acid structures within the polygalacturonic chain of pectin compounds. Accordingly, the success of $\mathrm{OH}$ group replacement by $-\mathrm{S}$ groups on sulfated pectin structures after the sulfation synthesis was performed was expressed as the degree of substitution. In the process of pectin sulfation, $\mathrm{OH}$ groups within polysaccharide chains were replaced by $-\mathrm{S}$ available in sulfation agent $\left(\mathrm{SO}_{3}-\mathrm{DMF}\right)$. Based on [24], the presence of free hydroxyl groups in an abundant number provide a certain substrate so as sulfation reactions occur. Jung et al. [4] reported their work that the sulfate content of a Pleurotus eryngii fungus polysaccharide derivation increased in line with the sulfation agent ratio. The DS value is highly affected by the sulfate content since the substitution process in the synthesis occurs between hydroxyl groups and sulfate groups. The DS value of polysaccharide is a notable parameter to evaluate its bioactivity [24]. This is because sulfate groups play an essential role in determining polysaccharide bioactivities.

Based on Figure 3 above, the sulfate content and the degree of substitution resulted from the treatment of $6.0-9.0-\mathrm{mL} \mathrm{SO} \mathrm{SO}_{3}-\mathrm{DMF}$ volume were lower than the treatment of $10.5-\mathrm{mL}$ and $12.0-\mathrm{mL} \mathrm{SO} \mathrm{SO}_{3}-\mathrm{DMF}$ volume. The use of $10.5-\mathrm{mL} \mathrm{SO}_{3}-\mathrm{DMF}$ volume produced values of the sulfate content and the degree of substitution relatively similar to the 12.0-mL treatment. Based on decision of balance result on characteristics i.e. sulfated percentage of $43.63 \%$ with the sulfate content of $0.302 \%$ and degree of sulfation of 
0.0155 , it was selected the treatment of $\mathrm{SO}_{3}-\mathrm{DMF}$ volume of $9.0 \mathrm{~mL}$. Sulfated pectin using 9.0-mL $\mathrm{SO}_{3}$-DMF volume showed better results than other treatments. Pectin which was resulted from 9.0-mL $\mathrm{SO}_{3}$-DMF volume possibility of providing sulfate content sufficient and safe for use in the production of sLMP nanoparticles with good characteristics and bioactivity.

\subsection{Sulfated LMP Nanoparticle Characterization}

To prove occurrence of the ionic gelation process from SLMP, the preliminary research step was carried out with the bead formation experiment using sLMP and the $\mathrm{CaCl}_{2}$ solution at low concentrations $(<1.0 \%)$. Macroscopically, the sLMP solution when dripping into the cation solution would be dispersed (bead not formed) and immediately settled. Pursuant to [4], solubility of sulfated polysaccharide in water undergoes an increase. This fact is due to the presence of groups containing sulfur within polymer structures enhancing the number of ionic groups. Then, the $\mathrm{CaCl}_{2}$ concentration was adjusted to $2 \%$ and $3 \%$. Results obtained were similar to the previous. Thus, preparation of a solution combination between non-sulfated LMP and sLMP at different ratios was performed. Observation results are presented in Table 1.

Table 1. Macroscopic Observation of Beads from Combination Sulfated and non Sulfated Low Methoxyl Pectin

\begin{tabular}{|l|c|c|c|c|c|}
\hline \multirow{2}{*}{$\begin{array}{c}\text { Cation } \\
\text { Concent. }\end{array}$} & \multicolumn{5}{|c|}{ Ratio of LMP:sLMP 0.3\% } \\
\cline { 2 - 6 } & $1: 1$ & $1: 2$ & $2: 1$ & $1: 4$ & $4: 1$ \\
\hline $\mathrm{CaCl}_{2} 2 \%$ & $\begin{array}{c}\text { Spherical } \\
\text { plate }\end{array}$ & $\begin{array}{c}\text { Concave } \\
\text { plate }\end{array}$ & $\begin{array}{c}\text { Spherical } \\
\text { plate }\end{array}$ & $\begin{array}{c}\text { Liquid, broken } \\
\text { spherical plate }\end{array}$ & $\begin{array}{c}\text { Spherical } \\
\text { plate }\end{array}$ \\
\hline $\mathrm{CaCl}_{2} \mathbf{3 \%}$ & $\begin{array}{c}\text { Spherical } \\
\text { plate } \\
\phi=0.75 \mathrm{~cm}\end{array}$ & Dispersed & $\begin{array}{c}\text { Spherical } \\
\text { plate } \\
\phi=0.5 \mathrm{~cm}\end{array}$ & Dispersed & $\begin{array}{c}\text { Spherical } \\
\text { plate } \\
\phi=0.5 \mathrm{~cm}\end{array}$ \\
\hline
\end{tabular}

Table 1 demonstrates that the ionic gelation occurring at ratios of LMP:sLMP 1:1, 2:1 and 4:1. However, to investigate sLMP effects in order to have good performance in biological activities the ratio of LMP:sLMP at 1:1 was selected (to obtain more sulfate groups within the particles). Measurement results in a composition of the pectin $2 \%$ and the cation $0.8 \%$ at $1: 1$ ratio were: (1) 643.5 (PDI 0.501); (2) 590.8 (PDI 0.728); (3) 577.5 (PDI 0.679) with a 603.9 (PDI 0.636) mean value. These results demonstrated that pectin particle sizes had reached the nanometric sizes (ranging $500-<1000 \mathrm{~nm}$ ).

To observe LMP:sLMP nanoparticle stability an observation on particle sizes during storing at $5^{\circ} \mathrm{C}$ cool temperature, $27^{\circ}-30^{\circ} \mathrm{C}$ room temperature and $40^{\circ} \mathrm{C}$ room temperature in 8 points (T0-T7) were carried out. The profile on a rate of particle size increase during storage time is presented in Figure 4. 


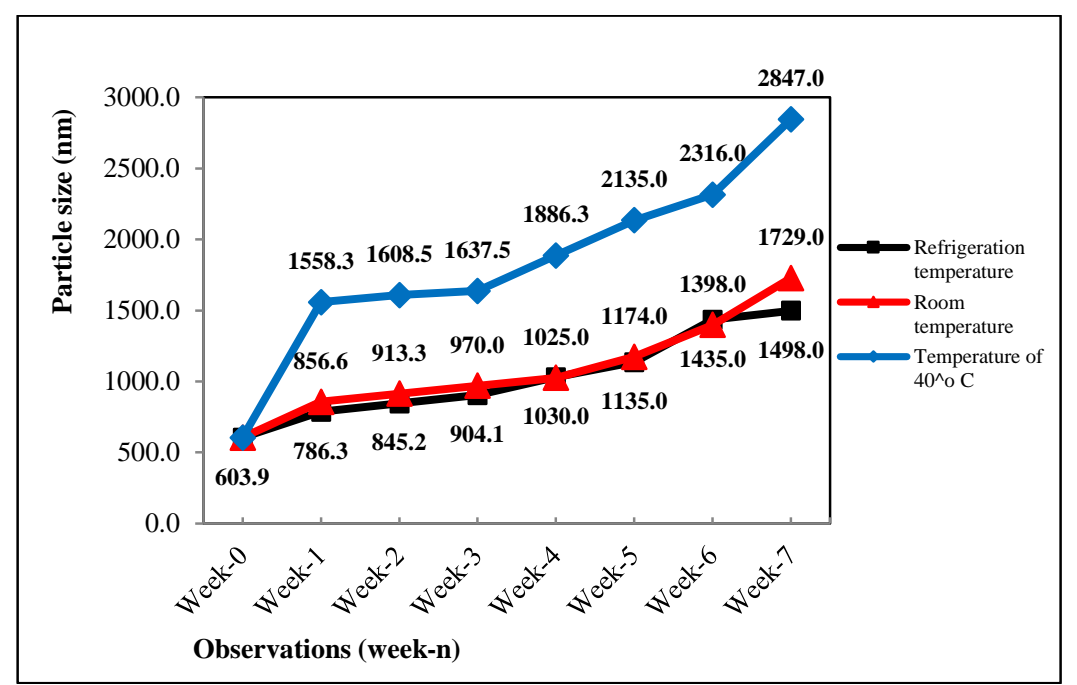

\section{Figure 4. Profile of Increasing Rate of Pectin Nanoparticle Size during Storage in Refrigeration Temperature, Room Temperature and Temperature of $40^{\circ} \mathrm{C}$ for 7 Weeks}

Based on Figure 4, it is evident that particle sizes underwent an increase during storage and rose sharply in hot-temperature storage. Dramatically increase in the size occurred in the particles storage at 40oC i.e. from $603.9 \mathrm{~nm}$ (Week-0) to $2847 \mathrm{~nm}$ (Week-7) with an increase of $2243.1 \mathrm{~nm}$. The storaging particles in cold and room temperature have a trend of increasing size relatively similar until Week- 6 with sloping pattern, i.e being $1398 \mathrm{~nm}$ (an increase of $794.1 \mathrm{~nm}$ ) and $1435 \mathrm{~nm}$ (an increase of $831.1 \mathrm{~nm}$ ) respectivelly. However, at Week-7 the particle size on room temperature storage rising more sharply (be $1729 \mathrm{~nm}$ ) compared to cold temperature (be $1498 \mathrm{~nm}$ ). One of factors depicting nanoparticle stability is the zeta potential. This value commonly is incorporated to show charge properties of a nanoparticle surface [25]. The zeta potential reflects electric potential of particles and is affected by the particle composition with medium where particles are dispersed [26]. A nanoparticle with the higher zeta potential than the absolute value of 30 $\mathrm{mV}$ appears stable in the suspension, so as the surface charges prevent occurrence of aggregation, results in good colloidal stability [27]. Jonassen et al. [20] reported that the chitosan nanoparticle/TPP zeta potential values of $<+30 \mathrm{mV}$ produced instability during storage in liquid resulting in a particle aggregation thereby allowing greater sizes. The zeta potential values of LMP:sLMP nanoparticles less than $-30 \mathrm{mV}$ ranged -15.2 to 16.6 $\mathrm{mV}$. This might be one causing factor of colloidal nanoparticle instability. Particles were aggregated during storage so as the sizes tended to increase.

Nanoparticle sizes of LMP:sLMP experiencing an increase might be also caused by the presence of aggregation induced by $\mathrm{Ca}$ at high temperature and aggregation due to hydrogen bonds at low temperature [28]. Perticles of LMP:sLMP stored at cool temperature and room temperature approached the value of one $\mu \mathrm{m}(1000 \mathrm{~nm})$ after storing for 4 weeks, whereas at hot temperature it had risen after stirring for one weeks. In addition, the storage at $20^{\circ} \mathrm{C}$ and $40^{\circ} \mathrm{C}$ experience a decrease in gel strength even though there are calcium ions [29]. Continuous heating at high temperature will lead to a pectin de-polymerization process which is a degradation resulted from hydrolysis on glycoside bonds [30], or $\beta$-elimination [31] contributing to a viscosity decrease. Macroscopically, a solution containing sulfated pectin nanoparticles becomes more dilute. Conforming to storability test results in three storage conditions it had better that LMP:sLMP nanoparticles are stored at cool temperature condition $(5 \mathrm{oC})$. 


\section{Conclusion}

Pectin was successfully sulfated shown by the presence of $-\mathrm{S}$ groups within pectin chains, in accordance with the FTIR analysis. The sulfation process with $\mathrm{SO}_{3}$-DMF 9.0 $\mathrm{mL}$ indicated the best results, i.e. $43.63 \%$ of the sulfated percentage with the $0.302 \%$ sulfate content and the 0.0155 -sulfation degree. Nanoparticles of sLMP could produced using combination of unsulfated LMP and sLMP. Sulfated pectin (sulfation using $\mathrm{SO}_{3}$ DMF $9.0 \mathrm{~mL}$ ) formed nanoparticles in a formula combination of LMP:sLMP (a ratio of $1: 1)$ with a composition of pectin of $2 \%$ and $\mathrm{CaCl}_{2}$ of $0.8 \%$. Nanoparticles of sulfated pectin (LMP:sLMP) was relatively stable at cool temperature storage.

\section{Acknowledgements}

The author expresses gratitude to Indonesian Agency for Research and Development that had provided research funds. Also thanks to Ida Farida who had assisted this research in the ICAPRD laboratory.

\section{References}

[1] F. J. Cui, W.Y. Tao, Z. H. Xu, W. J. Guo, H. Y. Xu, Z. H. Ao, J. Jin and Y. Q. Wei, "Structural analysis of anti-tumor heteropolysaccharide GFPS1b from the cultured mycelia of Grifola frondosa GF9801", Bioresour. Technology, vol. 98, (2007), pp. 395-401.

[2] S. L. Lai, Z. Y. Pan and X. F. Li, "Study on the degradability of chitosan under microwave irradiation", Journal of Shanxi University of Science \& Technology, vol. 23, (2005), pp. 38-40.

[3] S. L. Xiong, A. Li, N. Huang, F. Lu and D. Hou, "Antioxidant and immunoregulatory activity of different polysaccharide fractions from tuber of Ophiopogon japonicas", Carbohydrate Polymers, vol. 86, (2011), pp. 1273-1280.

[4] H.Y. Jung, I.Y. Bae, S. Lee and H.G. Lee, "Effect of the degree of sulfation on the physicochemical and biological properties of Pleurotus eryngii polysaccharides", Food Hydrocol, vol. 25, (2011), pp. 12911295 .

[5] S. Chen, C. Xue, L. Yin, Q. Tang, G. Yu and W. Chai, "Comparison of structures and anticoagulant activities of fucosylated chondroitin sulfates from different sea cucumbers", Carbohydrate Polymers, vol. 83, (2011), pp. 688-695.

[6] H. P. Vitor and P. A. S. Mourão, "Structure, biology, evolution, and medical importance of sulfated fucans and galactans", Glycobiology, vol. 18, (2008), pp. 1016-1027.

[7] A. Kydonieus, C. Elson and M. Thanou, "Drug delivery using sulfated chitonous polymers", US paten, (2004), pp. 20, 040, 038, 870.

[8] H. J. Martinichen, E. R. Carbonera, P. A. J. Gorina and M. Lacominia, "Anticoagulant and antithrombotic activity of a sulfate obtained from a glucan component of the Lichen parmotrema mantiqueirense Hale", Carbohydrate Polymers, vol. 60, (2005), pp. 7-13.

[9] Y. Wang, L. Zhang, Y. Li, X. Hou and F. Zeng, "Correlation of structure to antitumor activities of five derivatives of a beta-glucan from Poria cocos sclerotium", Carbohydrate Reseach, vol. 339, (2004), pp. 2567-2574.

[10] H. Zhang, Z. Y. Wang, L. Yang, X. Yang, X. Yang and Z. Zhang, "In vitro antioxidant activities of sulfated derivatives of polysaccharides extracted from Auricularia auricular", Int. J. Mol. Sci, vol. 12, (2011), pp. 3288-3302. doi:10.3390/ijms12053288.

[11] T. L. Nguyen, D. Wang, Y. Hu, Y. Fan, J. Wang, S. Abula, L. Guo, J. Zhang, S. K. Khakame and B.K. Dang, "Immuno-enhancing activity of sulfated Auricularia auricular polysaccharides", Carbohydrate Polymers, vol. 89, (2012), pp. 1117-1122.

[12] S. S. Wong, Z. R. J. Ngiam, S. Kasapis and D. Huang, "Novel sulfation of curdlan assisted by ultrasonication", International Journal of Biol. Macromol, vol. 46, (2010), pp. 385-388.

[13] F. V. Vityazew, V. V. Golovchenko, O. A. Patova, N. N. Drodz, V. A. Makarov and A. S. Shashkov, "Syntetis of sulfated pectins and their anticoagulant activity", Biochemistry, Moscow, vol. 75. (2010), p. 759.

[14] M. L Fernandez, D. M. Sun, M. A. Tosca and D. J. McNamara, "Citrus pectin and cholesterol interact to regulate hepatic cholesterol homeostasis and lipoprotein metabolism: a dose response study in guinea pigs", American Journal of Clinical Nutrition, vol. 59, (1994), pp. 869-878.

[15] S. E. Schwartz, R. A. Levine, R. S. Weinstock, R. S. Petokas, C. A. Mills and F. D. Thomas, "Sustained pectin ingestion: effect on gastric emptying and glucose tolerance in noninsulin dependent diabetic patients", American Journal of Clinical Nutrition, vol. 48, (1988), pp. 1413-1417. 
[16] E. Olano-Martin, G. H. Rimbach, G. R. Gibson and R. A. Rastall, "Pectin and pectic-oligosaccharides induce apoptosis in vitro human colonic adenocarcinoma cells", Anticancer Research, vol. 23, (2003), pp. 341-346.

[17] S. Hoejgaard, "Pectin Chemistry, Funcionality, and Applications", (2004).

[18] P. Opanasopit, A. Apirakaramwong, T. Ngawhirunpat, T. Rojanarata and U. Ruktanonchai, "Development and characterization of pectinate micro/nanoparticles for gene delivery", AAPS Pharm. Sci. Tech, vol. 9, (2008), pp. 67-74.

[19] J. Wang, L. Liu, Q. B. Zhang, Z. S. Zhang, H. M. Qi and P. C. Li, "Synthesized oversulphated, acetylated and benzoylated derivatives of fucoidan extracted from Laminaria japonica and their potential antioxidant activity in vitro", Food Chem, vol. 114, (2009), pp. 1285-1290.

[20] H. Jonassen, A. L. Kjoniksen and M. Hiorth, "Stability of chitosan nanoparticles cross-linked with tripolyphosphate", Biomacromolecules, vol. 13, (2012), pp. 3747-3756.

[21] L. Q. Yang and L. M. Zhang, "Chemical structural and chain conformational characterization of some bioactive polysaccharides isolated from natural sources", Carbohydr. Polym, vol. 76, (2009), pp. 349361.

[22] G. D. Manrique and F. M. Lajolo, "FT-IR spectroscopy as a tool for measuring degree of methyl esterification in pectins isolated from ripening papaya fruit", Postharvest Biology and Technol, vol. 25, (2002), pp. 99-107.

[23] C. Mähner, M. D. Lechner and E. Nordmeier, "Synthesis and characterisation of dextran and pullulan sulphate", Carbohydr. Res, vol. 331, (2001), pp. 203-208.

[24] X. Hu, A. Adamcakova-Dodd and P. S. Thorne, "The fate of inhaled 14C-labelled PCB11 and its metabolites in vivo", Environ. Int, vol. 63, (2014), pp. 92-100.

[25] P. Couvreur, G. Barrati, E. Fattal, P. Legrand and C. Vauthier, "Nanocapsule technology: A Review", Crit. Rev. Ther. Drug Carrier Syst, vol. 19, (2002), pp. 99-134.

[26] V. J. Mohanraj and Y. Chen, "Nanoparticles: A Review", Trop. Journal of Pharmaceutical Res, vol. 5, no. 1, (2006), pp. 561-573.

[27] C. Freitas and R. H. Muller, "Effect of light and temperatur on zeta potential and physical stability in solid lipid nanoparticle (SLNTM) dispersion”, International Journal Pharm, vol. 168, (1998), pp. 221229.

[28] X. Li, S. Al-Assaf, Y. Fang and G. O. Phillips, "Characterisation of commercial LM-pectin in aqueous solution”, Carbohydrate Polymers, vol. 92, (2013), pp. 1133-1142.

[29] G. A. Morris, J. Castile, A. Smith, G. A. Adams and S. E. Harding, "The effect of different storage temperature on physical properties of pectin solutions and gel”, Polymer Degradation and Stability, vol. 95, no. 12, (2010), pp. 2670-2673.

[30] K. Cheng and L. Y. Lim, "Insulin-loaded calcium pectinate nanoparticles: Effect of pectin molecular weight and formulation", Drug dev. Ind. Pharm, vol. 30, (2004), pp. 359-367.

[31] I. Fraeye, A. DeRoeck, T. Duverrer, I. Verlent, M. E. Hendrickx and A. VanLoey, "Influence of pectin properties and processing conditions on thermal pectin degradation", Food Chemistry, vol. 105, no. 2, (2007), pp. 555-563.

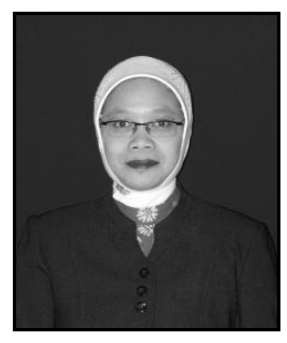

Sri Usmiati, she was born in Jakarta, Indonesia on November, 23, 1968. She obtained undergraduate degree from Padjadjaran University, Bandung, Indonesia in the year of 1994. The magister degree in technology of animal product was completed in 1998 from Bogor Agriculture University. The author is working as a researcher at Indonesian Center for Agricultural Postharvest Research and Development, in field of postharvest technology since 2003. She has published several research articles in the field of bioprocess engineering and postharvest technology. The research interest includes microbiology, enzymology, and fermentation.

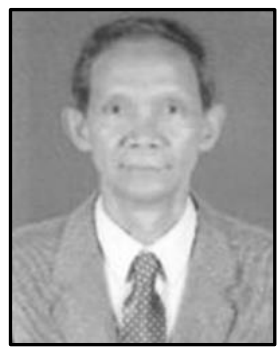

Djumali Mangunwidjaja, he was born in Temanggung, Central Java, July 20, 1950. In1980, he completed undergraduate on food technology in the Department of Agricultural Products Processing, Faculty of Agricultural Technology, Gadjah Mada University. His magister pursued in France on Bioprocess Engineering at the Institut National Polytechnique de Lorraine (INPL) Nancy in 1984 and a Doctorate in Biotechnology Industry from the Universite de 


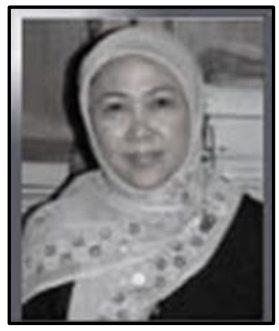

Nancy I. He was a Chairman of the Agroindustrial Technology, Faculty of Engineering and Technology, Bogor Agricultural University (1991-1994) and several other positions related to the development of research. The research is elaborated bioprocess polysaccharides, biosurfactant, and design of bioindustry and bioreactor. Some scientific work that stands out among others: Fructose production from dahlia tuber inulin by immobilized whole yeast cells in a packed bed bioreactor and development of immobilized cells as catalyst for the production of cyclodextrins from starch. He has written two books on Agricultural Technology and has patents on the hydrolysis of inulin.

Erliza Noor, she was born in Bandung, West Java, on February 2 , 1960. She completed her undergraduate study in Bandung Institute of Technology on Chemical Engineering in 1985. Her Doctorate degree acquired on Chemical Engineering from The University of Queensland, Australia in 1994. Prof. Dr. Ir. Erliza Noor is a professor in Agroindustrial Technology, Faculty of Agricultural Engineering and Technology in Bogor Agricultural University since December 2010 - Currently. Prof. Dr. Ir. Erliza Noor has published several research articles in the field of chemical engineering. One of her popular research is the production of fermentation coffee using several potential lactic acid bacteria (microbes).

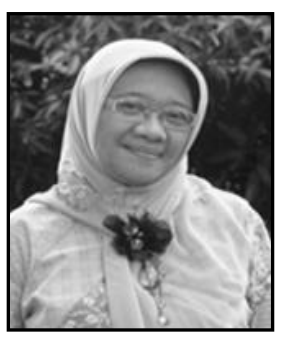

Nur Richana, she was born in Central Java, Indonesia on July, 25,1954 . She has obtained a BSc degree in Gajah Mada University and her M.Sc and Ph.D degree in the year 2006 from Bogor Agriculture University. She is working as a researcher in postharvest technology, at Indonesian Agency for Agricultural Research and Development, Ministry of Agriculture as a researcher since 1983. She also College research Profesor at Bogor Agriculture University and Gajah Mada University. She has published several research articles in the field of bioprocess engineering and postharvest technology. Her research interests include enzymology, fermentation and production of biofuels.

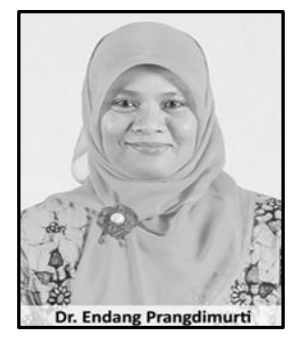

Endang Prangdimurti, she was born in Bogor, on July 23, 1968. Her undergraduate study in Food Technology obtained from Bogor Agricultural University, Indonesia. She continued in master and doctorete degree on Food Science in the same university. An area of expertise is Food biochemistry, with research Interests of evaluation of biological value of nutrient and non-nutrient, and development of functional foods from local resources. One popular publication was the effect of a cup of wood (Caesalpinia sappan Linn) extracts on the mouse splenocytes and K-562 cells proliferation, wich was published in Proceedings of the ASEAN Food Conference 2003 together with by D.R. Adawiyah and R.S. Puspaningrum 
International Journal of Bio-Science and Bio-Technology Vol.8, No.5 (2016) 